\section{Das berühmteste medizinische Buch}

\section{Iris Ritzmann}

Prof. Dr. med. et lic. phil., Mitglied der Redaktion Medizingeschichte

Selbstbewusst lässt er sich darstellen, Andreas Vesal, der als 28-Jähriger die Anatomie seiner Zeit revolutionierte. Sein Lehrbuch De Humani Corporis Fabrica (Über den Bau des menschlichen Körpers) darf als das berühmteste medizinische Buch aller Zeiten bezeichnet werden. Es kam erstmals 1543 heraus, im selben Jahr, in dem die These von Kopernikus das geozentrische Weltbild erschütterte. Die antike Anatomie, die auf Tiersektionen aufbaute und seit Jahrhunderten gelehrt wurde, enthielt Ungenauigkeiten und Fehler. Obschon die Kirche bereits zu Beginn des 14. Jahrhunderts die Zergliederung von menschlichen Leichen prinzipiell erlaubte, verhinderte der dogmatische universitäre Unterricht kritisches Hinterfragen und damit neue Sichtweisen.

Andreas Vesal, 1514 in Brüssel geboren, studierte Philosophie und Sprachen in Leyden, dann Medizin in Paris. Bereits während des Studiums hatte er sich Leichen beschafft und seziert. Direkt nach Abschluss seiner Dissertation wurde er an die angesehene Universität Padua berufen.

Mit der Fabrica schuf Vesal den ersten künstlerischen Anatomieatlanten. Vesal hatte die Herstellung der wunderschön ausgearbeiteten Holzschnitte, die dem Tizianschüler Stephan Kalkar zugeordnet werden, genau überwacht, damit die anatomischen Details exakt seinen Skizzen und den Beschreibungen im Text entsprachen. Den bei Johannes Oporinus in Basel gedruckten Foliant widmete er Kaiser Karl V., der ihn den zahlreichen Gegnern zum Trotz - zum Leibarzt erhob.

Die zweite Auflage, die 1555 in der damals topmodernen Garamond-Schrift gesetzt wurde, enthält zahlreiche Überarbeitungen des Autors. Das Frontispiz zeigt eine anatomische Sektion, die vor einem sakralen Bau im Freien stattfindet. Im Mittelpunkt steht Vesal und blickt uns direkt in die Augen. Die Darstellung steckt voller Metaphern: Ziege und Hund weisen auf die Überwindung der Tiersektionen hin, Dante in den Zuschauerreihen verweist auf das Weltengericht,

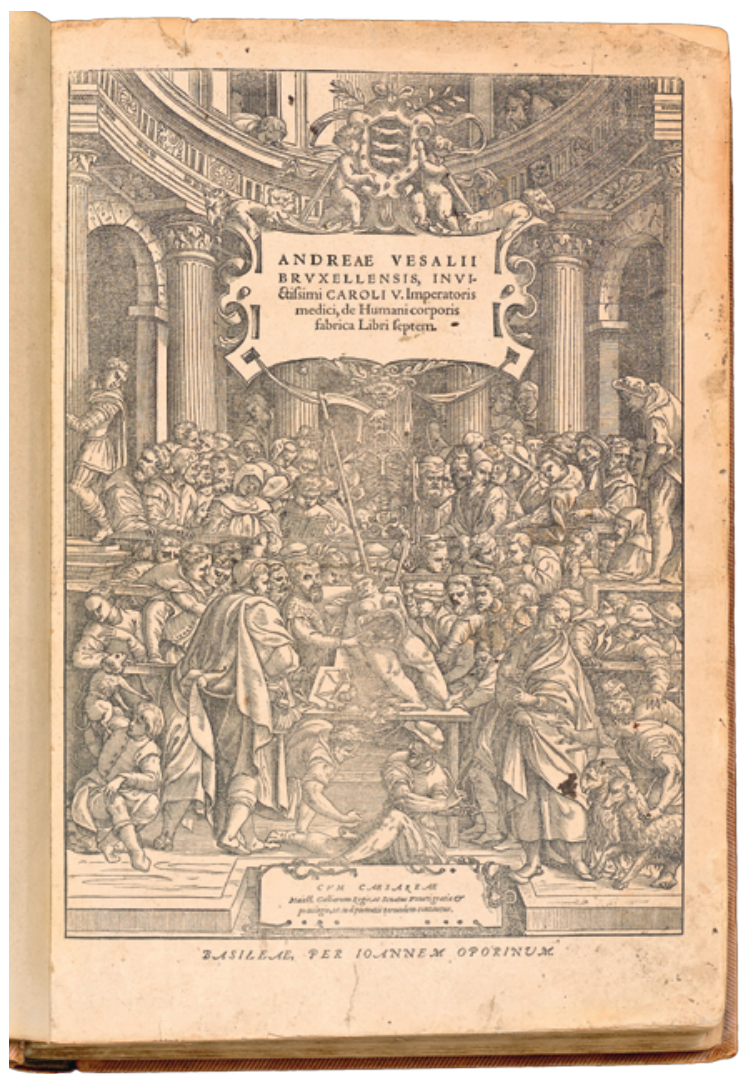

Frontispiz, in Andreas Vesal: De Humani Corporis Fabrica Libri Septem, 2. Aufl. Basel 1555, Sammlung Dr. Franz Käppeli.

schliesslich steht auch Vesal selbst nicht nur für die neue Autopsie: Seine Rechte weist in der Bauchhöhle des liegenden weiblichen Körpers auf die Gebärmutter, den Ursprung allen Lebens. Die Linke dagegen streckt den Zeigefinger in Richtung Skelett, das mit der Sense als Zeichen des personifizierten Todes ans Ende allen Lebens erinnert. Das Titelbild führt nicht nur in das anatomische Meisterwerk ein, es wirkt zugleich als Memento mori.

\section{Bildnachweis}

(c) Museum für medizinhistorische Bücher Muri (mmbm.ch) 